\title{
Consideraciones sobre la datación de morteros de cal mediante ${ }^{14} \mathrm{C}$
}

Francisco Javier Alejandre Sánchez | Dpto. Construcciones Arquitectónicas II, ETSIE, U. de Sevilla

URL de la contribución <www.iaph.es/revistaph/index.php/revistaph/article/view/4098>

\section{RESUMEN}

A pesar de que pueden existir dudas por parte de algunos investigadores sobre la inclusión de las técnicas de datación dentro de la caracterización de los morteros históricos, aportar su antigüedad de fabricación o elaboración permite la adscripción cronológica del elemento constructivo del que forma parte (muros, fábricas, revestimientos, etc.), información importante para complementar las hipótesis históricas o arqueológicas, por lo que parece lógica su integración dentro de la herramientas arqueométricas de caracterización de estos materiales de construcción.

Dentro de las técnicas instrumentales disponibles actualmente que datan mediante ${ }^{14} \mathrm{C}$, se expondrá la espectrometría de masas con acelerador de partículas AMS (Accelerator Mass Spectrometry), que se vale de la determinación del cociente isotópico ${ }^{14} \mathrm{C} /{ }^{12} \mathrm{C}$ para el cálculo de la edad. Es el método más moderno y que consigue medidas de mayor calidad, empleando a su vez menos cantidad de muestra (decenas de miligramos). Con esta metodología es posible fechar muestras de hasta 50.000 años de antigüedad, siendo un sistema de datación totalmente afianzado en la comunidad científica.

Se indicarán los componentes del mortero de cal conteniendo ${ }^{14} \mathrm{C}$ que son susceptibles de datar, las precauciones durante la toma de muestras y los errores intrínsecos y extrínsecos que se deben considerar en el análisis de los resultados.

\section{Palabras clave}

AMS (Accelerator Mass Spectrometry) | C-14 | Cal | Carbonatación | Datación | Mortero | 


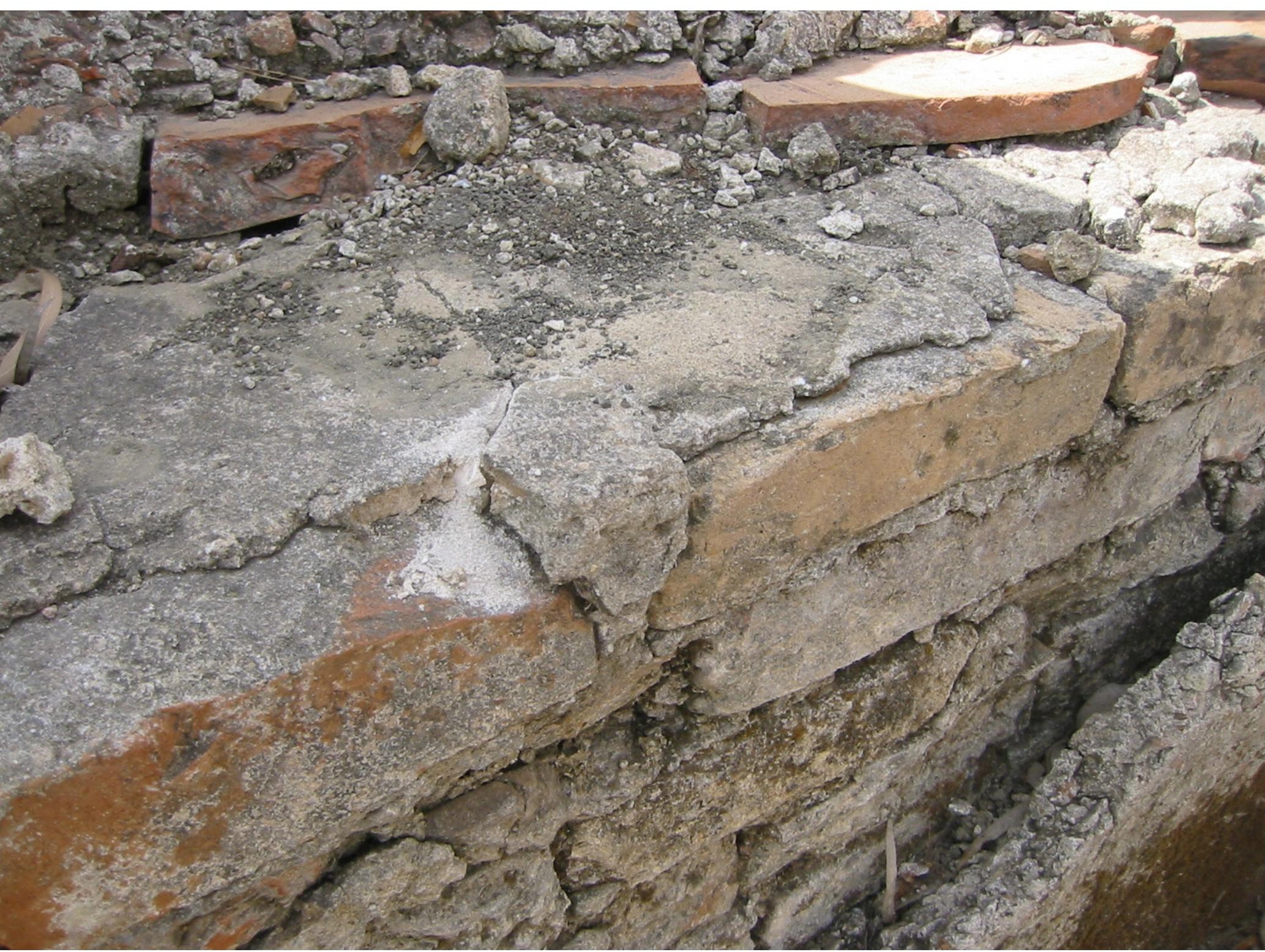

Muro romano en el enclave arqueológico de Carteia, San Roque (Cádiz) | foto Francisco Javier Alejandre Sánchez 


\section{INTRODUCCIÓN}

La adscripción cronológica de elementos y estructuras arquitectónicas es uno de los principales problemas a los que se enfrentan historiadores, arqueólogos, arquitectos, restauradores, etc., sobre todo cuando estas construcciones o sus restos no pueden ser analizados mediante métodos tipológicos, estilísticos o datos historiográficos, que aporten algunas indicaciones relativas al período de su ejecución. Por este motivo, para determinar la edad de un edificio o de restos arqueológicos se han ido incorporando distintas disciplinas (ceramología, palinología, antracología, carpología, estratigrafía, micro y macrofauna, etc.) y técnicas instrumentales (radiocarbono, dendrocronología, luminiscencia TL/OSL, arqueomagnetismo, etc.) (SANJURJOSÁNCHEZ, 2016). Según Hale, Heinemeier, Lancaster et ál (2003), en ausencia de técnicas instrumentales para determinar la edad absoluta, la única opción es apoyarse en datos históricos y marcadores arqueológicos, que a menudo requieren la presencia de artefactos para ser empleados a modo de "guía fósil".

Los morteros son materiales de construcción ampliamente utilizados con fines constructivos en edificios, monumentos y obras de arte, y tanto por su composición como por su sistema de fabricación mantienen el potencial de ser utilizados para la datación mediante carbono 14. Ya desde la década de los 60 del s. XX, investigadores como Delibrias y Labeyrie (1964); Folk y Valastro (1976); Van Strydonck, Dupas, Dauchot-Dehon et ál. (1986); Heinemeier, Jungner, Lindroos et ál. (1997); Hale, Heinemeier, Lancaster et ál. (2003); Nawrocka, Michniewicz, Pawlyta et ál. (2005); Marzaioli, Lubritto, Nonni et ál. (2011); Marzaioli, Nonni, Passariello et ál. (2013); Nonni, Marzaioli, Secco et ál. (2013), entre otros, han puesto a prueba la posibilidad de realizar dataciones radiocarbónicas precisas, proporcionando estudios con nuevas metodologías que han mejorado la exactitud de los resultados progresivamente (RINGBOM; LINDROOS; HEINEMEIER et ál. 2014; MARZAIOLI; NONNI; PASSARIELLO et ál. 2013; NONNI, MARZAIOLI; SECCO et ál. 2013).

Quirós Castillo, Marzaioli y Lubritto (2011) indican la oportunidad de aplicar la herramienta de datación de morteros mediante C-14, constituyendo un posible punto de ruptura en el actual conocimiento porque:

1. Los morteros son un tipo de materiales muy extendidos en las excavaciones arqueológicas.

2. La datación de morteros, en principio, representa un ancla cronológico imparcial para el estudio de edificios y otras estructuras fechados con anterioridad indirectamente por medio de materiales orgánicos que se encuentran, cuando están presentes, en el contexto del sitio de estudio. 
Finalmente, a pesar de que pueden existir algunas dudas sobre la inclusión de las técnicas de datación dentro de lo que es propiamente la caracterización de los morteros, se debe considerar que aportan su antigüedad/época de fabricación, información sumamente importante para complementar las hipótesis historiográficas o arqueológicas, por lo que parece lógico su consideración dentro de las técnicas de caracterización.

\section{PRINCIPIOS DE LA DATACIÓN MEDIANTE CARBONO 14}

El método de datación por radiocarbono o carbono-14 $\left({ }^{14} \mathrm{C}\right)$ es un sistema fiable y afianzado en la comunidad científica que se ha empleado desde las décadas 50-60 de s. XX para conocer la edad de muestras orgánicas de menos de 50.000 años. El principio en el que se basa es la ley de decaimiento exponencial del isótopo ${ }^{14} \mathrm{C}$, que se genera continuamente en la atmósfera como consecuencia del bombardeo de átomos de nitrógeno por neutrones producidos por los rayos cósmicos al interaccionar con la atmósfera, según la siguiente reacción:

$\mathrm{n}+{ }_{7}^{14} \mathrm{~N} \rightarrow{ }_{6}^{14} \mathrm{C}+\mathrm{p}$

Se llega de esta forma a un equilibrio de formación-degradación de ${ }^{14} \mathrm{C}$, isótopo que se encuentra homogéneamente mezclado con los átomos estables y no radiactivos del carbono $\left({ }^{12} \mathrm{C}\right.$ y $\left.{ }^{13} \mathrm{C}\right)$ que están combinados químicamente con el oxígeno en forma de $\mathrm{CO}_{2}$. Posteriormente la fotosíntesis incorpora el ${ }^{14} \mathrm{C}$ en las plantas, manteniendo una proporción ${ }^{14} \mathrm{C} /{ }^{12} \mathrm{C}$ en éstas igual a la atmosférica. Continuando con la cadena trófica, los animales incorporan a sus cuerpos por ingestión el carbono de las plantas. Tras la muerte de los seres vivos no se incorpora nuevo ${ }^{14} \mathrm{C}$ a los tejidos, y la concentración del isótopo va decreciendo conforme se transforma en ${ }^{14} \mathrm{~N}$ por desintegración radiactiva:

Desintegración $\beta_{6}^{-14} \mathrm{C} \rightarrow{ }_{7}^{14} \mathrm{~N}+{ }_{-1}^{0} \mathrm{e}+\mathrm{v}_{\mathrm{e}}$

La masa en ${ }^{14} \mathrm{C}$ de cualquier espécimen decrece exponencialmente a un ritmo bien conocido: a los 5730 años de su muerte la cantidad de ${ }^{14} \mathrm{C}$ en sus restos se ha reducido a la mitad. Por eso, midiendo la cantidad de radiactividad en una muestra o determinando la cantidad de ${ }^{14} \mathrm{C}$ que aún queda, se puede datar el momento de la muerte del ser vivo. Esto se conoce como "edad radiocarbónica" y se expresa en años BP (Before Present), escala que equivale a los años que han pasado desde la muerte del espécimen hasta el año 1950 de nuestro calendario (fecha elegida por convenio y porque en la segunda mitad del siglo XX los ensayos nucleares provocaron severas anomalías en las curvas de concentración relativa de los isótopos radiactivos en la atmósfera).

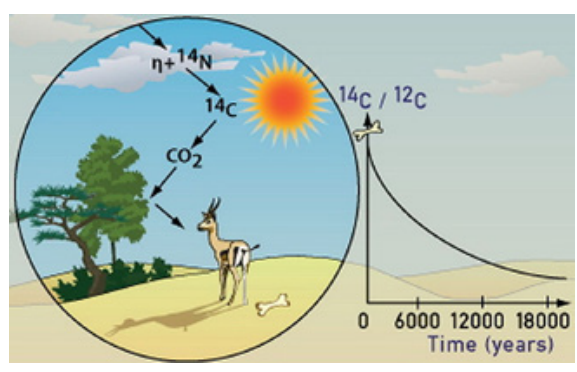

Imagen 1. Formación, incorporación y decaimiento del ${ }^{14} \mathrm{C}$ | fuente DOUMA, 2008 
Como se ha comentado anteriormente los resultados obtenidos por esta técnica se suelen expresar en años antes del presente BP, lo que significa que $t(B P)=-t$.

La edad de una muestra sin corregir vendrá dada por la expresión:

$t(B P)=-1 / \lambda \cdot \ln N / N_{0} \circ \quad t(B P)=-t_{\text {avg }} \cdot \ln N / N_{0} \quad 0 \quad t(B P)=-t_{1 / 2} \cdot \log _{2} N / N_{0}$

Donde:

$\mathrm{N}_{0}=$ número de átomos de ${ }^{14} \mathrm{C}$ en el momento $\mathrm{t}=0$, o sea el momento inicial en el que se empieza a contar el número de desintegraciones,

$\mathrm{N}$ = número de átomos restante después de que haya transcurrido un tiempo $\mathrm{t}$,

$\Lambda=$ constante de desintegración radiactiva, la probabilidad de desintegración por unidad de tiempo,

Vida media $t_{\text {avg }}=1 / K$, siendo para el ${ }^{14} \mathrm{C} t_{\text {avg }}=8033$ años

Periodo de semidesintegración $t_{1 / 2}=t_{\text {avg }} \cdot \ln 2$, siendo para el ${ }^{14} \mathrm{C}_{1 / 2}=5568$ años Libby (1955)

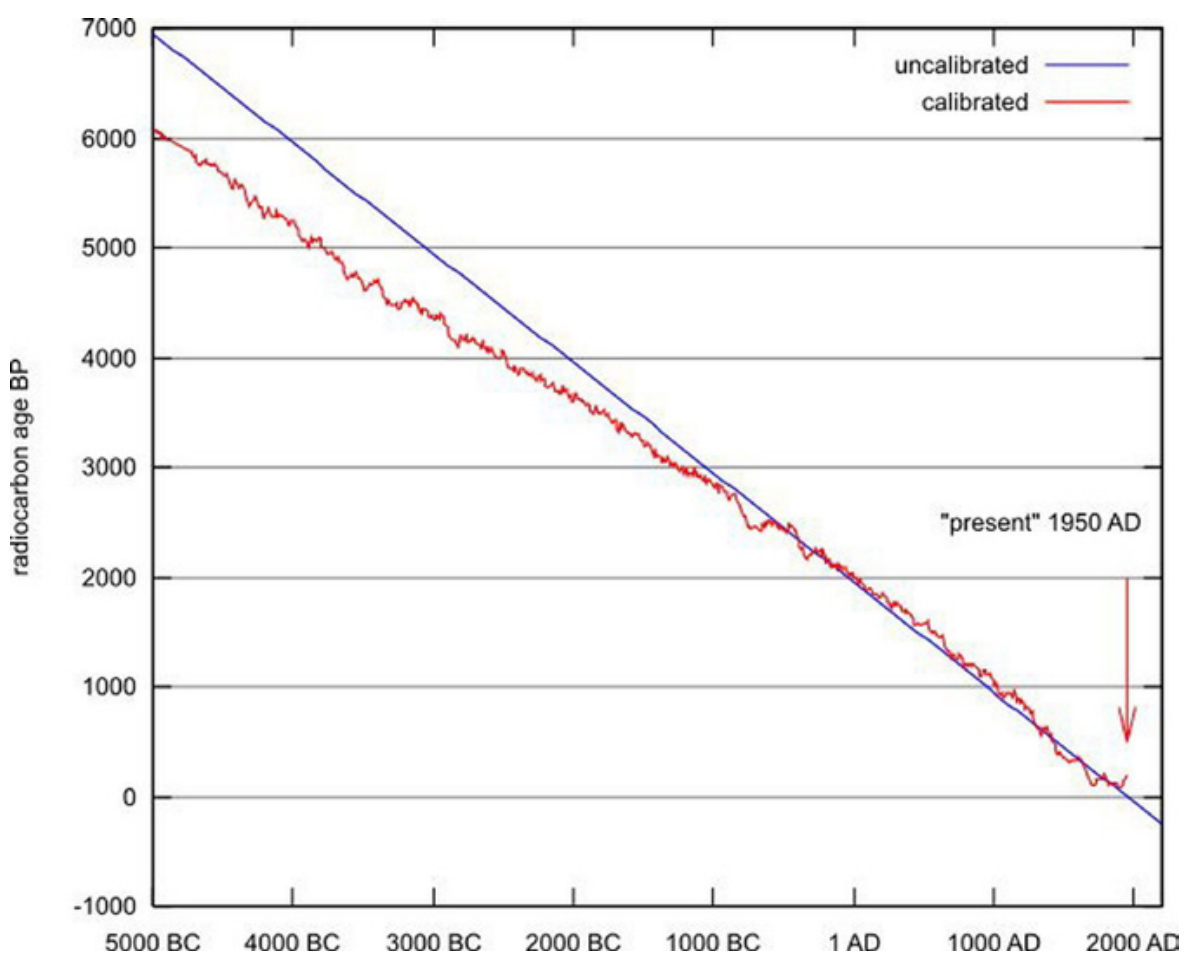




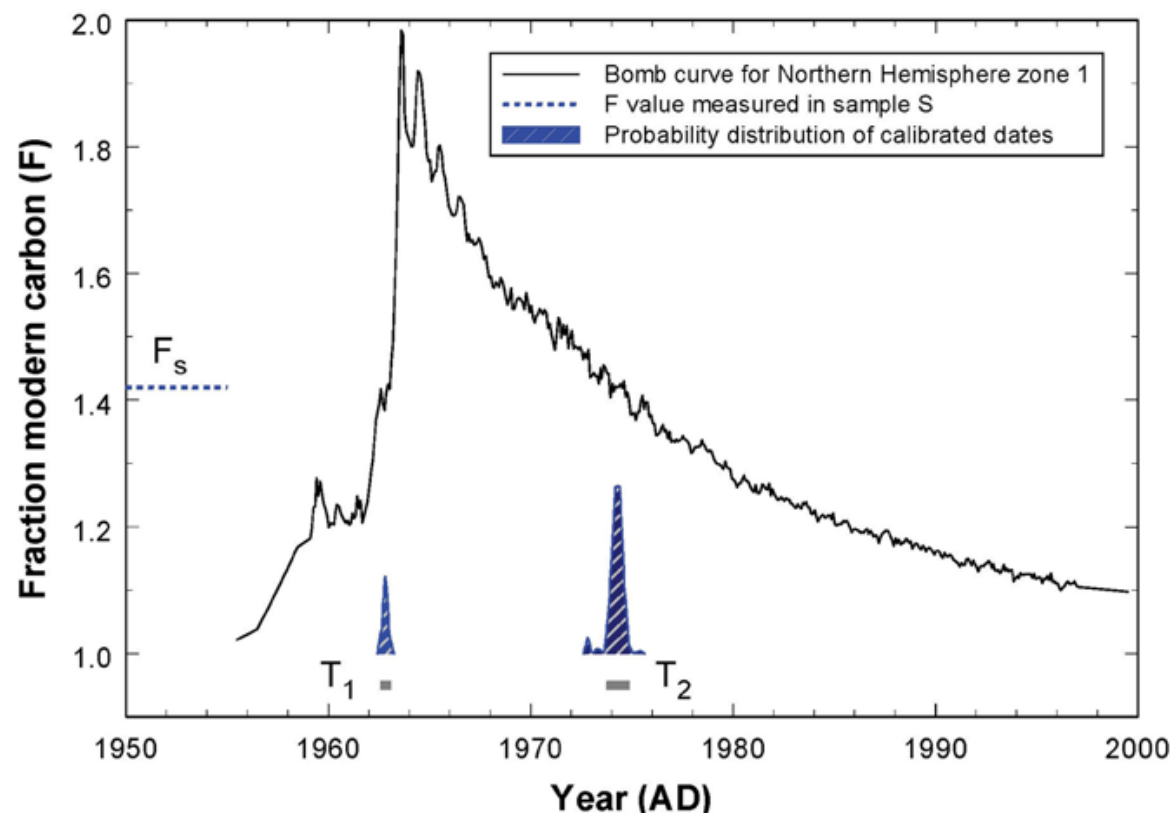

Una vez calculada la edad de la muestra medida en años BP, se procede a la obtención de la edad cronológica mediante la correspondiente curva de calibración. Comparando las concentraciones teóricas de ${ }^{14} \mathrm{C}$ con las de muestras de maderas de edades conocidas con dendrocronología, se observaron diferencias con los resultados esperados, que se debían a que la concentración de ${ }^{14} \mathrm{C}$ en la atmósfera también ha variado respecto al tiempo, por lo que puede corregirse esa estimación de edad comparándola con curvas obtenidas mediante interpolación de datos conocidos. La edad así hallada se denomina "edad calibrada" y se expresa en años Cal BP (imagen 2).

Entre los años 50 y 60 del s. XX la concentración de ${ }^{14} \mathrm{C}$ se duplicó como consecuencia de las pruebas nucleares atmosféricas, por lo que se ha definido otra curva para el periodo que va desde 1950 hasta la actualidad (imagen 3).

\section{PARÁMETROS DE INTERÉS EN LA INTERPRETACIÓN DE LOS RESULTADOS DE UNA DATACIÓN DE ${ }^{14} \mathrm{C}$}

Una vez que se han obtenido los datos a través de la medida y realizado su posterior análisis numérico, para una correcta interpretación de toda la información suministrada existe una serie relevante de parámetros relativos a la muestra (SANTOS, 2018a):
Imagen 3. ${ }^{14} \mathrm{C}$ atmosférico en hemisferio norte zona 1 para el periodo AD 1955-2000 | fuente HUA, 2009: 382; BARBETTI; HUA, ZOPPI et ál., 2004 
> Edad Radiocarbono Convencional (ERC): es el dato que se obtiene a partir de la medida y el tratamiento numérico posterior. Al expresarse siempre en unidades BP, no indica de manera directa la edad de la muestra, por lo que hay que llevar a cabo la calibración, lo que nos dará edades realmente relacionadas con el calendario.

Su error se expresa como $\pm \sigma$ en una distribución gaussiana (habitual en medidas físicas). Por las propiedades de esta distribución, esto quiere decir que con un $68 \%$ de probabilidad, la ERC real de la muestra estará entre X- $\sigma$ $<$ ERC $<X+\sigma$, y con un 95\%, la ERC real de la muestra estará entre $X-2 \sigma$ $<E R C<X+2 \sigma$. Es decir, cuanto más ampliamos el rango sobre el valor de ERC obtenido, es más probable que el valor verdadero esté dentro de ese rango. Habitualmente se toma el caso de $2 \sigma$.

Por convenio, todas las muestras que den valores menores a 200 BP se consideran modernas, debido a que por la forma de la curva de calibración, no es posible asignarle una edad posteriormente. De forma práctica nos indica que las muestras que realmente tengan menos de 300 años aproximadamente no son buenas candidatas a la datación por ${ }^{14} \mathrm{C}$.

> pM: es un parámetro previo al cálculo de la ERC y es, por tanto, equivalente. Simplemente, es una forma de expresar la cantidad de radiocarbono en tanto por ciento, siendo el $100 \%$ el correspondiente al año 1950. Es especialmente útil en muestras en las que no se pretende directamente la datación, sino que se trata de blancos (que tendrán pM muy cercano a cero) o de muestras patrón, en las que no interesa la edad, sino su concentración de radiocarbono. En concreto, en estos casos, no es raro que pM sea mayor que $100 \%$. Asimismo, en muestras recientes afectadas por el pulso de ${ }^{14} \mathrm{C}$ generado en las pruebas nucleares de mediados del s. XX, son normales valores de hasta $170 \%$

$>\delta^{13} \mathrm{C}$ : parámetro de gran importancia para realizar una de las correcciones habituales en el cálculo de la ERC. Se mide en \% con respecto a un patrón y es una característica del material. Es indicativo de que no todos los materiales orgánicos tienen la misma composición isotópica, es decir, la relación entre los isótopos del carbono, ${ }^{12} \mathrm{C},{ }^{13} \mathrm{C}$ y ${ }^{14} \mathrm{C}$, no es constante en la naturaleza. Por ejemplo, valores típicos de madera son $\sigma^{13} \mathrm{C} \sim-25 \%$, mientras que muestras marinas pueden mostrar valores del orden de $\sigma^{13} \mathrm{C} \sim+1 \%$.

\section{Ejemplo de gráfica y valores de calibración}

En el recuadro con la calibración y en la gráfica se haya la información más relevante, estando ambos están íntimamente relacionados. En el primero encontramos el resultado de transformar la edad de radiocarbono convencional $(E R C)$ a la edad de calendario, son rangos de fechas a los que 
puede pertenecer la muestra y se representan junto a la probabilidad de pertenencia.

\section{Ejemplo}

Edad de Radiocarbono convencional $565 \pm 45$ BP

Con un $68 \%$ de probabilidad, la ERC real de la muestra está entre 610 y 520 $\mathrm{BP}$, y con un $95 \%$ de probabilidad entre 655 y 475 BP.

\begin{tabular}{|l|l|}
\hline $\begin{array}{l}\text { Calibración } 1 \sigma(68 \% \text { probabilidad): } \\
\text { (Comienzo: fin) Área relativa }\end{array}$ & $\begin{array}{l}\text { (1316 AD:1355 AD) } 0.565533 \\
\text { (1389 AD:1418 AD) } 0.434467\end{array}$ \\
\hline $\begin{array}{l}\text { Calibración } 2 \sigma(95 \% \text { probabilidad): } \\
\text { (Comienzo: fin) Área relativa }\end{array}$ & (1298 AD:1371 AD) 0.569285 \\
\hline
\end{tabular}

La distribución gaussiana de la ERC se representa en el eje vertical, y se pueden observar los rangos de $\pm 1 \sigma$ y $\pm 2 \sigma$ (líneas paralelas y simétricas respecto al centro de la gaussiana. El proceso de calibración consiste básicamente en cruzar esta distribución con la curva de calibración y proyectar estos cortes en el eje horizontal. De este modo, obtenemos en el eje horizontal, en escala de calendario, los diferentes rangos con su probabilidad. Dado que la calibración la podemos hacer tomando $\sigma$ o $2 \sigma$ en la ERC, tenemos dos conjuntos. Como está indicado, tomar el resultado de $2 \sigma$ nos da un $95 \%$ de probabilidad. Así, en el ejemplo que nos ocupa, si tomamos el caso $2 \sigma$, tendremos un primer rango, 1298-1371 AD, con una probabilidad de $56.9285 \%$, y un segundo rango de $1379-1433$ AD con un $43.0715 \%$ de probabilidad (imagen 4).

En este caso tenemos dos rangos con una probabilidad muy similar entre sí, aunque esto no tiene por qué ser siempre así, en ocasiones puede haber un único rango posible, y en otras puede haber múltiples rangos con diferentes probabilidades. La decisión última de cuál de los rangos es el más adecuado sólo puede hacerse basándonos en otros datos de medidas, o en evidencias históricas que nos permitan eliminar alguno de los rangos.

La forma de la curva de calibración (imágenes 2 y 4) va modificándose a lo largo de los siglos, pudiendo ser casi vertical con mucha pendiente, casi horizontal, con picos, etc., lo que va a condicionar el número de rangos de edad calibrada que se forman por interpolación, su amplitud y probabilidad. 


\section{Radiocarbon Age vs. Calibrated Age}

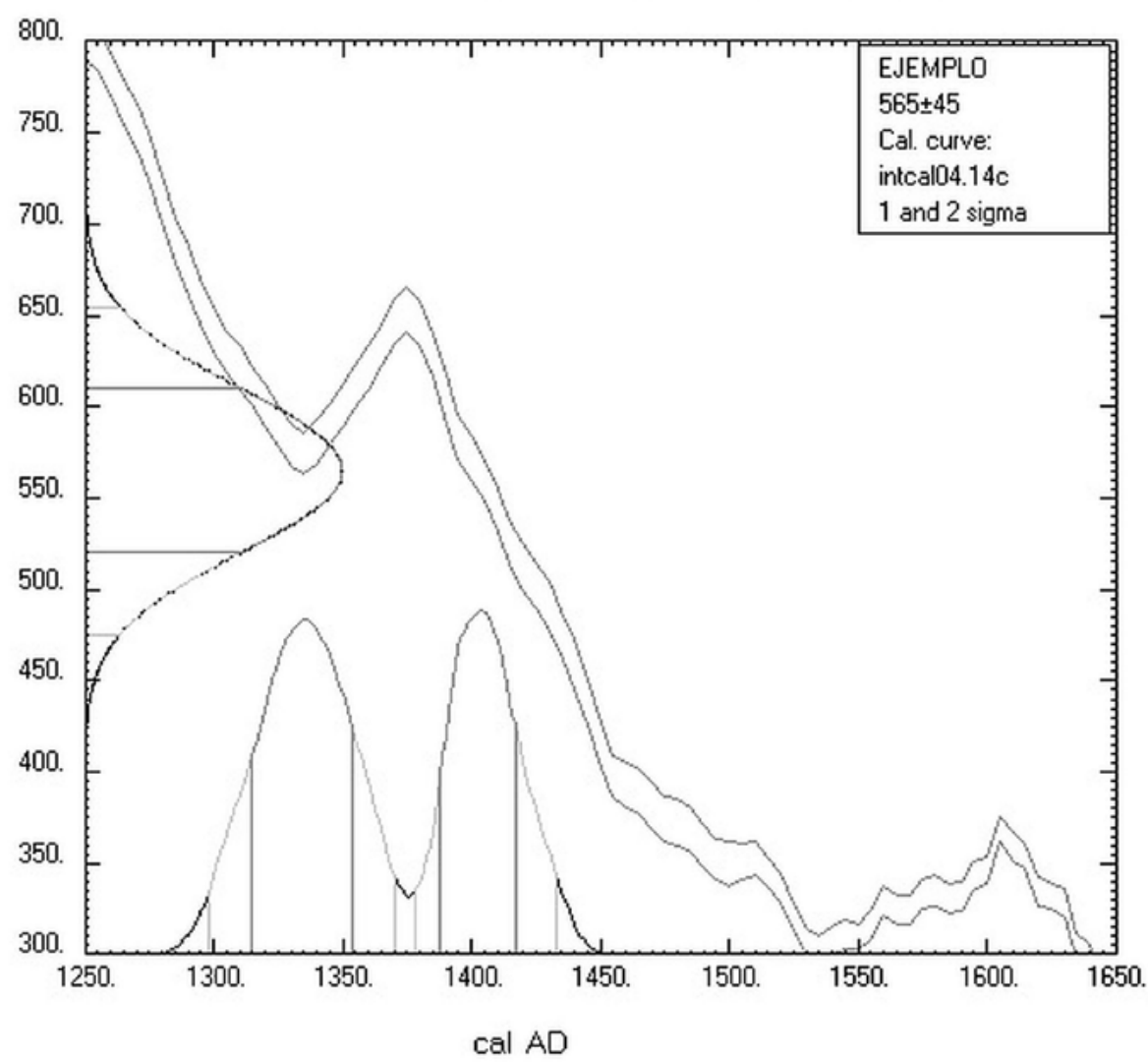

Imagen 4. ERC vs. edad calibrada para el ejemplo 2 | fuente SANTOS ARÉVALO, 2018a

Este es uno de los principales errores intrínsecos de esta técnica de datación y que deriva de que la concentración de ${ }^{14} \mathrm{C}$ en la atmósfera no es constante a lo largo del tiempo, variando en función de los cambios naturales producidos en la intensidad de la radiación cósmica, existencia de reservorios de materia orgánica en los océanos que modifican el flujo del carbono en función del clima terrestre, o de procesos antrópicos, como la emisión de grandes cantidades de $\mathrm{CO}_{2}$ como consecuencia de la actividad industrial desde el principio de la revolución industrial en el siglo XVIII hasta los años 50 del siglo $\mathrm{XX}$, que hicieron que la concentración de ${ }^{14} \mathrm{C}$ disminuyera como consecuencia de la emisión y la quema de grandes cantidades de combustibles fósiles (efecto Suess).

Como ejemplos de errores intrínsecos derivados de la forma de la curva podemos citar el periodo que va del siglo XVIII al siglo XX que es bastante horizontal y genera intervalos amplios de datación con poca resolución, y las dataciones a partir del año 1960 que generan siempre dos intervalos de probabilidad (imagen 3). 


\section{TÉCNICAS INSTRUMENTALES PARA LA DATACIÓN}

Hoy en día se emplean tres técnicas instrumentales para medir el contenido de ${ }^{14} \mathrm{C}$ en una muestra; las dos primeras son radiométricas, ya que miden la radiación emitida al desintegrarse el isótopo, mientras que la tercera se basa en la separación de los isótopos de carbono:

1. Contador proporcional de gas. Es la técnica originalmente desarrollada por Libby (1955) consistente en un detector de partículas ionizantes fuertemente blindado para evitar la radiación natural, que mide el número de desintegraciones producidas en una muestra que se ha transformado en $\mathrm{CO}_{2}$. Sus inconvenientes consisten en que con la baja actividad del ${ }^{14} \mathrm{C}$ y su pequeñísima concentración en la muestra, los contadores sólo son capaces de detectar un número muy bajo de desintegraciones por segundo y mol, por lo que es necesario un tiempo muy largo de medición así como muestras más grandes (sobre $1 \mathrm{~kg}$ ).

2. Contador de centelleo líquido. En esta técnica, muy extendida en los años sesenta del siglo XX, la muestra se disuelve en benceno añadiendo un líquido que centellea al producirse una desintegración, teniendo un rendimiento mayor que los proporcionales de gas. Las desventajas son que continúan afectados por el problema de la baja actividad del ${ }^{14} \mathrm{C}$ y de la radiación ambiental.

3. Espectrometría de masas con acelerador (AMS). Es la técnica más moderna, en ella la muestra previamente grafitizada se ioniza e introduce en un acelerador de partículas. El haz resultante es desviado por fuertes campos magnéticos y considerando que cada isótopo de carbono $\left({ }^{14} \mathrm{C},{ }^{13} \mathrm{C},{ }^{12} \mathrm{C}\right)$ tiene diferente masa, el ángulo de deflexión es ligeramente diferente para cada uno, siendo posible medir sus concentraciones relativas, determinando el coeficiente isotópico ${ }^{14} \mathrm{C} /{ }^{12} \mathrm{C}$ que suele estar entre $10^{-12}$ y $10^{-15}$. No depende de la actividad de la muestra y es insensible a la radiactividad natural, por lo que se pueden conseguir medidas de mayor calidad, además disminuye la cantidad de muestra necesaria (decenas de miligramos) y el tiempo de medida (típicamente 45 minutos). Los isótopos que habitualmente se determinan mediante AMS son, entre otros, ${ }^{10} \mathrm{Be},{ }^{14} \mathrm{C},{ }^{26} \mathrm{Al},{ }^{36} \mathrm{Cl},{ }^{41} \mathrm{Ca},{ }^{129} \mathrm{l}$ e isótopos de $\mathrm{Pu}$.

En la actualidad se han desarrollado aceleradores dedicados exclusivamente a datación por ${ }^{14} \mathrm{C}$ denominados MICADAS (Mini radioCarbon Dating System) fabricado en el ETH (Swiss Federal Institute of Technology Zurich), por su Laboratorio de Física de Haces de lones. Estos sistemas son extremadamente reducidos en tamaño y complejidad en relación con el acelerador Tandetrón de $1 \mathrm{MV}$, utilizan rangos de energías más bajos para radiocarbono, en torno a $200 \mathrm{kV}$, con el consiguiente empleo de sistemas más compactos para ello. Como conclusión, el uso de estos nuevos aceleradores 
permitirá el empleo de instrumentación más reducida de tamaño, barata y simple para AMS.

\section{Tratamientos para la preparación de las muestras}

Para poder realizar con garantías una datación por ${ }^{14} \mathrm{C}$ es necesario asegurar en todo momento que las muestras a analizar no son contaminadas por carbono externo, ya que esto podría modificar sensiblemente los resultados. Para ello es conveniente seguir en la medida de lo posible unas sencillas pautas que se detallan a continuación (SANTOS, 2018b):

$>$ La muestra debe mantenerse alejada del polvo, papel $u$ otros materiales modernos que pudieran adherirse (no es aconsejable envolver la muestra directamente en papel).

$>$ La manipulación de las muestras puede hacerse con normalidad, siguiendo las normas de higiene básicas en la manipulación de material científico. Es aconsejable, aunque no imprescindible, usar guantes.

$>$ Guardar las muestras en bolsas nuevas y limpias de plástico con autocierre (bolsas zip) o en viales nuevosy limpios de vidrio o plástico. También puede utilizarse papel de aluminio.

> Al empaquetar las muestras en viales o bolsas, asegurarse de que no se romperán en el transporte, utilizando plástico de embalaje (plástico de burbujas) o similar.

> En la siguente tabla se detalla la cantidad mínima de muestra recomendada de material seco según la matriz (no es aconsejable ceñirse al mínimo requerido). Las cantidades indicadas son aproximadas para obtener alrededor de $1 \mathrm{mg}$ de $\mathrm{C}$ en el punto final de la preparación.

\begin{tabular}{|l|l|}
\hline Tipo de muestra & Cantidad (en miligramos) \\
\hline Madera & 30 \\
\hline Carbón vegetal & 20 \\
\hline Textil, cuero, papel & 30 \\
\hline Microfósiles (plantas, tejido animal) & 20 \\
\hline Turba, sedimentos, suelos & variable \\
\hline Muestras de carbonato & 20 \\
\hline Conchas, corales & 50 \\
\hline Foraminíferas & 20 \\
\hline Huesos & $1-2$ gramos \\
\hline
\end{tabular}


Muestras de madera, carbón vegetal, semillas, textil, papel, cuero La primera etapa en el laboratorio es la limpieza AAA con disoluciones de $\mathrm{HCl}, \mathrm{NaOH}$, y neutralizando con agua destilada, y que tiene por objetivo eliminar los restos de carbonatos y ácidos orgánicos (húmicos, fúlvicos, etc.). Posteriormente se procede a su combustión en un analizador elemental, transformándose en dióxido de carbono $\mathrm{CO}_{2}$, gas que se somete a un proceso de grafitización según la siguiente reacción catalizada por el Fe a $580^{\circ} \mathrm{C}$ :

$\mathrm{CO}_{2}+2 \mathrm{H}_{2} \rightarrow \mathrm{C}+2 \mathrm{H}_{2} \mathrm{O}$

El grafito depositado sobre el hierro se prensa en una pastilla que está ya lista para la medida en el AMS.

\section{Muestras de carbonatos, moluscos, caracoles}

Este tipo de muestras, compuestas fundamentalmente por $\mathrm{CaCO}_{3}$, se purifican con un lavado rápido con ácido clohidrico, después se atacan con una disolución de ácido fosfórico al $80 \%$. El $\mathrm{CO}_{2}$ continúa el proceso de grafitización descrito anteriormente.

\section{Muestras de huesos}

En este caso se realiza en primer lugar un ataque con ácido clorhídrico que disuelve la fracción mineral y permite que se puedan separar las proteínas presentes en el hueso, de las que se purifica el colágeno, proteína que se combustiona para transformar en $\mathrm{CO}_{2}$, que continúa el proceso de grafitización descrito anteriormente.

\section{COMPONENTES SUSCEPTIBLES DE DATACIÓN EN LOS MORTEROS DE CAL}

Las definiciones actuales de morteros nos indican que son materiales de construcción compuestos de uno o varios conglomerantes inorgánicos, áridos de diámetro inferior a $4 \mathrm{~mm}$, pudiendo incorporar aditivos y adiciones (UNE-EN 998-1:10 y UNE-EN 998-2:12). Para los morteros históricos puede haber ciertas anomalías, sus componentes habituales son:

> Conglomerantes: cal aérea, cal hidráulica, yeso y barro (arcillas).

> Áridos de tamaño y naturaleza variable: silícea (cuarzo), silicatada (feldespatos, micas, arcillas), carbonatados (calizas, mármoles, dolomías...), etc.

> Adiciones: puzolánicas, cerámicas, pigmentos, fibras vegetales, etc.

> Inertes: carbón vegetal, madera, semillas, huesos, conchas y moluscos, etc. 
De estos componentes son susceptibles de datación mediante ${ }^{14} \mathrm{C}$ todos aquellos que contengan carbono de naturaleza orgánica (fibras de origen vegetal, madera, huesos, carbón vegetal, semillas, etc.) o de carbono inorgánico en forma de carbonatos que no tengan un origen geológico (cal carbonatada, moluscos, caracoles, etc.). Las rocas carbonatadas de origen geológico, tanto sedimentario (calizas y dolomías) como metamórfico (mármoles) tienen antigüedades muy superiores a los 50.000 años, por lo tanto carecen de ${ }^{14} \mathrm{C}$ al haberse desintegrado en su totalidad, son por tanto fuentes de ${ }^{12} \mathrm{C}$ o carbono muerto (death carbon DC) que conducen a incertidumbres por sobreestimación de la edad.

Los morteros con adiciones hidráulicas (vidrios inorgánicos) también se han datado pero con muchas complicaciones y con una baja tasa de éxito (RINGBOM; HALE; HEINEMEIER et ál., 2006; RINGBOM; HEINEMEIER; LINDROOS et ál., 2011; HODGINS; LINDROOS; RINGBOM et ál., 2011; LINDROOS; HEINEMEIER; RINGBOM et ál., 2011), aunque se han abierto nuevas perspectivas con las investigaciones de Michalska y Czernik (2015).

\section{Cal carbonatada}

Los morteros de cal (imágenes 6a y 6b) durante su proceso de carbonatación absorben $\mathrm{CO}_{2}$ atmosférico, incorporando el ${ }^{14} \mathrm{C}$ presente en la atmósfera, registrando por tanto el tiempo de construcción de un elemento en una matriz de $\mathrm{CaCO}_{3}$ secundario de origen antropogénico (VAN STRYDONCK; DUPAS; DAUCHOT-DEHON et ál., 1986) (imagen 5). Aunque el proceso de carbonatación es lento, ocurre dentro de periodos temporales asumibles dentro del error de la técnica de datación.

Según Quirós Castillo, Marzaioli, Lubritto et ál., 2011 et al. (2011), la evidencia científica indica que existe una serie de incertidumbres atribuibles mayoritariamente a la producción de mortero de cal y a los procesos de exposición ambiental:

1. Residuos de calizas (restos de la calcinación) que pueden tener su origen en la incompleta cocción (carbonato primario) durante la producción de cal viva (CaO), añadiendo $\mathrm{DC}\left(\sin { }^{14} \mathrm{C}\right)$ conduciendo a sobreestimaciones de edad;

2. arenas calcáreas que generan un efecto de envejecimiento similar al residuo de $\mathrm{C}$ muerto del carbonato primario;

3. áridos de cualquier tipo de material: ladrillos reutilizados, mármol, restos de piedras; $y$

4. agua circulante que contiene $\mathrm{CO}_{2}$ disuelto y puede causar un depósito suplementario (carbonatos terciarios) en el mortero o un intercambio en 


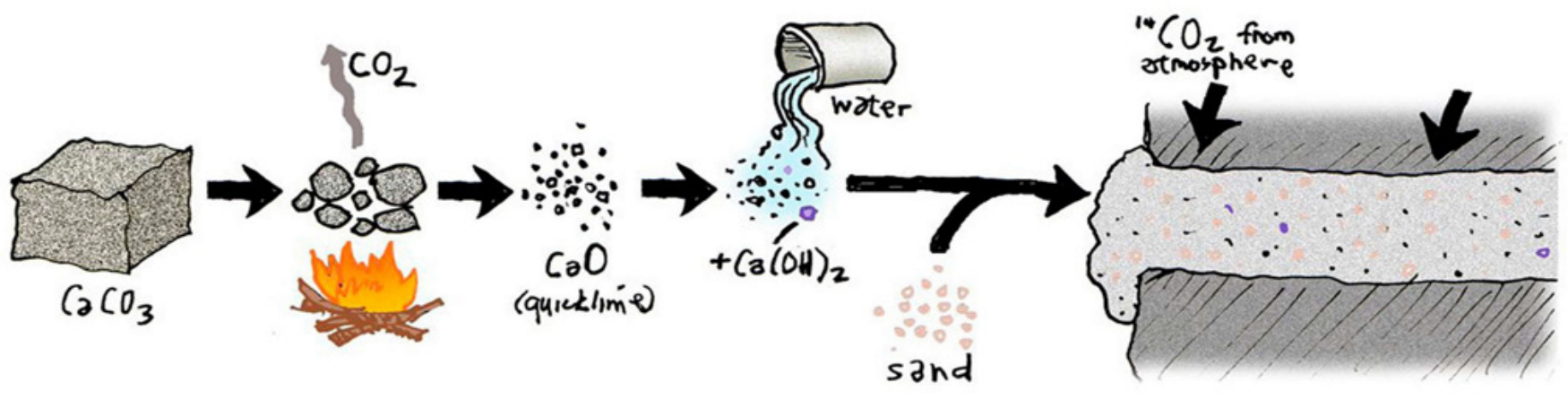

iones carbonato. Este efecto puede resultar en envejecimiento o en rejuvenecimiento de la edad.

Imagen 5. El mortero de cal absorbe dióxido de carbono de la atmósfera, lo que lo hace potencialmente adecuado para la datación mediante ${ }^{14} \mathrm{C}$ | fuente HALE; HEINEMEIER; LANCASTER et ál., 2003: 132

El error de la presencia de carbonato primario (geológico) depende lógicamente de su cantidad, así un $1 \%$ de ese C introduce una diferencia (en muestras de menos de 10.000 años) de 80 años, un 2\% introduce 160 años, un 5\% introduce casi 400 años, y así más o menos lineal. Con 1\% de C muerto, una muestra de 1000 años parecería de 1080, una de 2000, de 2080, y una de 10000 parecería de 10080.

Para solucionar el problema de la contaminación del carbonato geológico, principalmente procedente del árido o de la cal incompletamente cocida, se ha desarrollado dos líneas metodológicas:

1. Una, desarrollada inicialmente por Folk y Valastro (1976), consiste básicamente en la trituración y tamizado del mortero para eliminar el árido inerte, pretratamiento de hidrólisis ácida para desprender el $\mathrm{CO}_{2}$ y separación de la primera fracción menos contaminada por carbonato geológico, ya que la cal carbonatada conglomerante de origen antropogénico está formada por granos irregulares y pobremente cristalinos que se disuelven más rápidamente. Trabajos posteriores han testado y refinado dicha metodología modificando las fracciones granulométricas del tamizado, el tratamiento de hidrólisis ácida, y las fracciones gaseosas separadas y ensayadas, típicamente de 2 a 5 (HEINEMEIER; JUNGNER; LINDROOS et ál., 1997; RINGBOM; HALE; HEINEMEIER et ál., 2006; RINGBOM; LINDROOS; HEINEMEIER et ál., 2014; LINDROOS; ORSEL; HEINEMEIER et ál., 2014).

2. En el año 2011, el Centre for Isotopic Research on Cultural and Environmental heritage (CIRCE) en Italia desarrolló un procedimiento de purificación denominado "CryoSonic: Cryobraking, Sonication, Centrifugation" (criofragmentación, sonicación y centrifugación) con el objetivo de disminuir la concentración de DC procedente del árido o cal mal cocida (MARZAIOLI; LUBRITTO; NONNI et ál., 2011; MARZAIOLI; NONNI; PASSARIELLO et ál., 2013) con resultados satisfactorios y validado por 


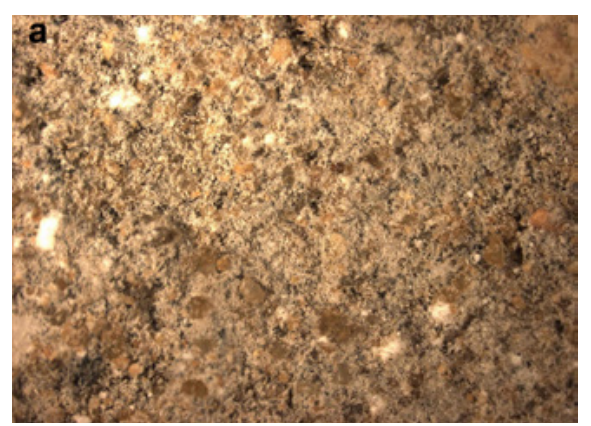

Imagen 6. a) Nódulos de cal carbonatada, b)

Conglomerante de cal carbonatada, c) Fragmentos de carbón vegetal | fotos Javier Alejandre
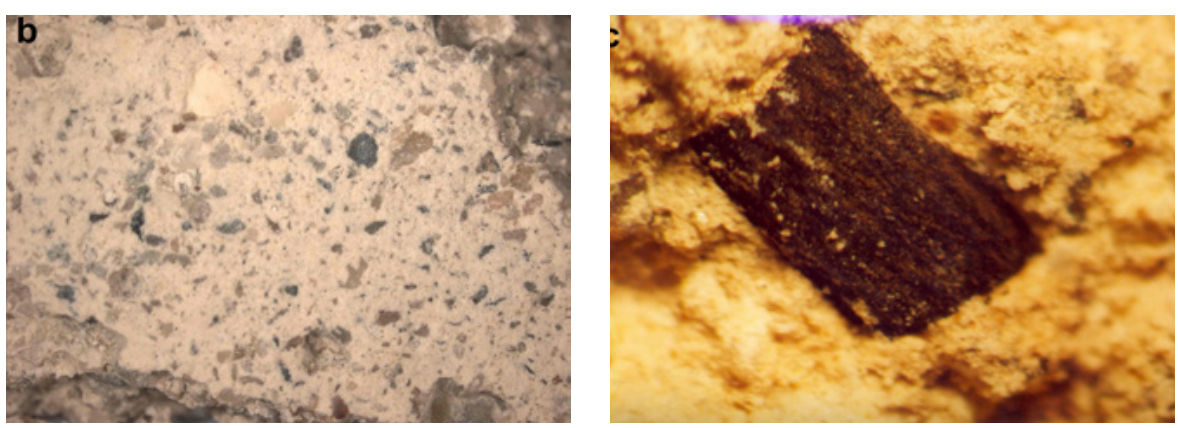

otros investigadores (QUIRÓS CASTILLO; MARZAIOLI; LUBRITTO et ál., 2011). Carmine, Caroselli, Lugli et ál. (2015) proponen nuevas mejoras del procedimiento consistentes en la división en dos etapas del proceso de sonicación (Cryo2SoniC) para mejorar la eliminación del C exógeno al mortero.

\section{Carbón vegetal}

El carbón vegetal en los morteros puede tener dos orígenes: el proceso de cocción de la cal en hornos artesanales que queman leña, y la incorporación de cenizas y restos inquemados de hogueras realizadas por albañiles en la obra. Es frecuente encontrar fragmentos de carbón embebidos en morteros y tapiales (imágenes $6 \mathrm{c}$ y $6 \mathrm{~d}$ ), siendo fácilmente reconocibles por su color negro y porque tiznan. Puede ser un buen componente susceptible de datación tal y como se indica en los trabajos de Berger (1992); Heinemeier, Jungner, Lindroos et ál. (1997); Gallo; Fieni; Martini et ál. (2000); Marzaioli, Nonni, Passariello et ál. (2013); Al-Bashaireh (2015); Michalska y Czernik (2015); y Sanjurjo-Sánchez (2016), una vez sea convenientemente tratado, aunque su empleo puede conducir a sobreestimaciones (TUBBS; KINDER, 1990): que no sea coetáneo con el proceso de fabricación del mortero y que proceda de especies vegetales de lento desarrollo vegetativo (anillos centrales de olivos, encinas, pinos, etc.) (RINGBOM; HALE; HEINEMEIER et ál., 2006).

\section{Madera}

Su presencia en morteros puede tener múltiples orígenes: agujas empleadas en los procesos de encofrado (tapiales), cuñas insertadas en las fábricas, restos de marcos de puertas y ventanas, etc. Se trata de unos de los materiales de construcción de naturaleza orgánica más empleados en las dataciones mediante ${ }^{14} \mathrm{C}$ (SANJURJO-SÁNCHEZ, 2016), aunque su empleo puede conllevar dos tipos de sobreestimación: que no sea coetánea con el proceso de fabricación del mortero y que proceda de especies vegetales de lento desarrollo vegetativo. 


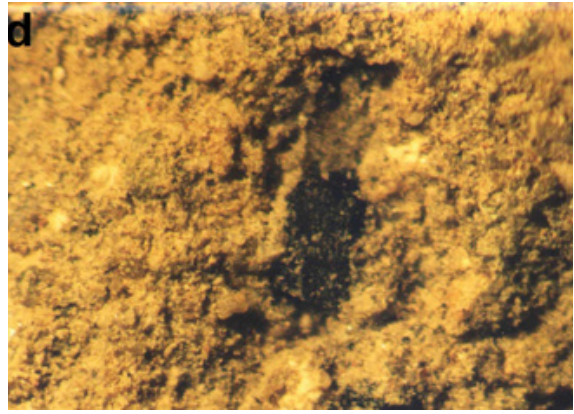

\section{Fibras vegetales}

La adición de fibras vegetales (paja, barcia) en los morteros para mejorar propiedades (resistencia a flexión, fisuración) ha sido frecuente desde tiempos históricos. Si están presentes en el mortero (imagen 6e) son componentes muy útiles ya que proceden de especies vegetales de corto desarrollo vegetativo y suelen ser coetáneas al proceso de fabricación por su escasa durabilidad.

\section{Caracoles (terrestres). Conchas de moluscos (marinos)}

Estos elementos pueden dar origen tanto a la cal conglomerante como formar parte de la arena empleada en la confección del mortero. En el primer caso, existen trabajos que indican que si la cocción de las conchas es adecuada para que no quede restos de carbono muerto, son adecuadas para la datación (Lindroos et ál., 2014). En la segunda situación, además de la incertidumbre de la coetaneidad (los exoesqueletos suelen ser muy duraderos una vez que ha muerto el ser vivo), hay que considerar otros efectos como la incorporación de carbonato geológico (carbono muerto ${ }^{12} \mathrm{C}$ ) del ambiente (sobreestimación de edad) y el efecto reservorio marino (las fechas radiocarbónicas de un organismo terrestre y marino de edad equivalente tienen una diferencia de cerca de 400 años de radiocarbono).

\section{CONCLUSIONES}

La revisión bliblográfica realizada indica que la metodología de datación mediante ${ }^{14} \mathrm{C}$ es aplicable a los morteros de cal, siendo dos los posibles orígenes de este isótopo en estos materiales de construcción: los componentes que contienen carbono de naturaleza orgánica (fibras de origen vegetal, madera, huesos, carbón vegetal, etc.) y los que contienen en carbono inorgánico en forma de carbonatos (cal carbonatada, moluscos, caracoles, etc.). El empleo de la técnica más moderna, la espectrometría de masas con acelerador (AMS) y los aceleradores dedicados exclusivamente a data-

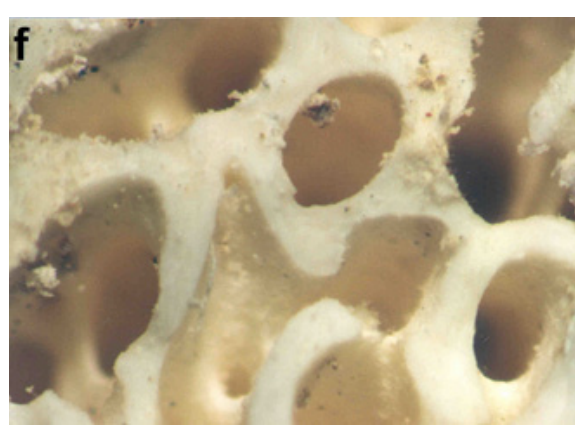

Imagen 6. d) Fragmentos de carbón vegetal, e) Fibra vegetal y f) Fragmento óseo | fotos Javier Alejandre 
ción por ${ }^{14} \mathrm{C}$ denominados MICADAS (Mini radioCarbon Dating System) permiten obtener resultados con muestras del orden de decenas de miligramos.

Los errores principales que se pueden producir y que hay que considerar cuando se realiza la datación de morteros mediante ${ }^{14} \mathrm{C}$ pueden ser de naturaleza intrínseca y extrínseca. Dentro de los primeros está la forma de la curva de calibración, que va modificándose a lo largo de los siglos debido a que la concentración de ${ }^{14} \mathrm{C}$ en la atmósfera no ha sido constante a lo largo del tiempo, lo que va a condicionar el número de rangos de edad calibrada que se forman por interpolación, su amplitud y probabilidad. Respecto a los extrinsecos, en los morteros destaca la presencia de áridos carbonatados de origen geológico, con antigüedades muy superiores a los 50.000 años y sin contenido en ${ }^{14} \mathrm{C}$ por haberse desintegrado en su totalidad, constituyendo la principal interferencia por su aporte de ${ }^{12} \mathrm{C}$ o DC, pero se han desarrollado procedimientos para disminuir su concentración y por tanto su interferencia, consiguiéndose resultados satisfactorios. También y dentro de este segundo grupo de errores, hay que indicar que componentes datables como el carbón, madera, huesos, etc. pueden conducir a dos sobreestimaciones de edad: que no sean coetáneos con el proceso de fabricación del mortero al proceder de una reutilización, y que tengan su origen en especies vegetales de lento desarrollo vegetativo.

Agradecimientos

A Francisco Javier Santos Arévalo, titulado superior para investigación del CSIC, responsable de la datación radiocarbónica del Centro Nacional de Aceleradores, por su colaboración. 


\section{BIBLIOGRAFÍA}

- AL-BASHAIREH, K. (2015) Radiocarbon Age Determinations of Mosaic Mortar Layers of Churches from North Jordan. Radiocarbon, vol 57, n. ${ }^{\circ} 5,2015$, pp. 851-863

- BARBETTI M.; HUA, Q.; ZOPPI, U.; FINK, D.; ZHAO, Y.; THOMSON, B. (2004) Radiocarbon variations from the Southern Hemisphere, 10,350-9700 cal BP. Instruments and Methods in Physics Research, Section B: Beam Interactions with Materials and Atoms, 223-224, pp. 366370

- BERGER, R. (1992) ${ }^{14} \mathrm{C}$ dating mortar in Ireland. Radiocarbon, vol. 34, n. ${ }^{\circ}$ 3, 1992, pp. 880-889

- CARMINE, L.; CAROSELLI, M.; LUGLI, S.; MARZAIOLI, F.; NONNI, S.; MARCHETTI DORI, S.; TERRASI, F. (2015) AMS radiocarbon dating of mortar: The case study of the medieval UNESCO site of Modena. Instruments and Methods in Physics Research, Section B: Beam Interactions with Materials and Atoms, 361, 2015, pp. 614-619

- DELIBRIAS, J.; LABEYRIE G. (1964) Dating of old mortars by the Carbon-14 Method. Nature, vol. 201, 742, 1964

- DOUMA, M. (conservador) (2008) Dating works. Pigments through the Ages [en línea] <http://www. webexhibits.org/pigments/> [Consulta: 01/03/2016]

- FOLK, R. L.; VALASTRO, S. (1976) Successful Technique for Dating of Lime Mortar by Carbon-14. Journal of Field Archaeology, vol 3, n. ${ }^{\circ} 2$, 1976, pp. 195-201

- GALLO, N.; FIENI, L.; MARTINI, M.; SIBILIA, E. (2000) Building archaeology, $14 \mathrm{C}$ and thermoluminescence: two examples comparison. En ÉVIN, J. (dir.) $14 \mathrm{C}$ et archéologie: 3e congrès international, Lyon, 6-10 avril 1998. Paris: Société préhistorique française, 1999, pp. 425-431 (Mémoire de la Société préhistorique française; 26)

- HALE, J.; HEINEMEIER J.; LANCASTER L.; LINDROOS, A.; RINGBOM Å. (2003) Dating Ancient Mortar. American Scientist, 91, 2003, pp. 130-137

- HEINEMEIER, J.; JUNGNER, H.; LINDROOS, A.; RINGBOM, A.; VON KONOW, T.; RUD. N. (1997) AMS 14C dating of lime mortar. Instruments and Methods in Physics Research, Section B: Beam Interactions with Materials and Atoms, 123, 1997, pp. 487-495

- HODGINS, G.; LINDROOS, A.; RINGBOM, Å.; HEINEMEIER, J.; BROCK F. (2011) ${ }^{14} \mathrm{C}$ dating of Roman mortars-preliminary tests using diluted hydrochloric acid injected in batches. En RINGBOM, Å.; HOHLFELDER, R. L. (ed.) Building Roma Aeterna. Current Research on Roman Mortar and Concrete. Commentationes Humanarum Litterarum 128, 2011, pp. 209-213 (Proceedings of the conference, Roma, 27-29/03/2008)

- LIBBY, W. F. (1955) Radiocarbon dating. 2nd edition.

\section{Chicago: University of Chicago Press, 1955}

- LINDROOS, A.; HEINEMEIER, J.; RINGBOM, A.; BROCK, F.; SONCK-KOOTA, P., PEHKONEN, M.; SUKSI, J. (2011) Problems in radiocarbon dating of Roman pozzolana mortars. En RINGBOM, Å.; HOHLFELDER, R. L. (ed.) Building Roma Aeterna. Current Research on Roman Mortar and Concrete. Commentationes Humanarum Litterarum 128, 2011, pp. 214-230 (Proceedings of the conference, Roma, 27-29/03/2008)

- LINDROOS, A.; ORSEL, E.; HEINEMEIER, J.; LILL, J.O.; GUNNELIUS, K. (2014) Radiocarbon dating of Dutch mortars made from burned shells. Radiocarbon, 56 (3), 2014, pp. 959-968

- LINDROOS, A.; HEINEMEIER, J.; RINGBOM, A.; BROCK, F.; SONCK-KOOTA, P.; PEHKONEN, M.; SUKSI, J. (2011) Problems in radiocarbon dating of Roman pozzolana mortars. En RINGBOM, Å.; HOHLFELDER, R. L. (ed.) Building Roma Aeterna. Current Research on Roman Mortar and Concrete. Commentationes Humanarum Litterarum 128, 2011, pp. 214-230

- MARZAIOLI, F.; LUBRITTO, C.; NONNI, S. PASSARIELLO, I.; CAPANO, M.; TERRASI, F. (2011) Mortar radiocarbon dating: preliminary accuracy evaluation of a novel methodology. Anal Chemistry, 83 (6), 2011, pp 2038-2045

- MARZAIOLI, F.; NONNI, S.; PASSARIELLO, I.; CAPANO, M.; RICCI, P.; LUBRITTO, C.; DE CESARE, N.; ERAMO, G.; QUIRÓS CASTILLO, J. A.; TERRASI, F. (2013) Accelerator mass spectrometry ${ }^{14} \mathrm{C}$ dating of lime mortars: Methodological aspects and field study applications at CIRCE (Italy). Nuclear Instruments and Methods in Physics Research, Section B: Beam Interactions with Materials and Atoms, 294, 2013, pp. 246-251

- MICHALSKA, D.; CZERNIK, J. (2015) Carbonates in leaching reactions in context of ${ }^{14} \mathrm{C}$ dating. Nuclear Instruments and Methods in Physics Research, Section B: Beam Interactions with Materials and Atoms, 361, 2015, pp. 431-439

- NAWROCKA, D.; MICHNIEWICZ, J.; PAWLYTA, J.; PADZUR, A. (2005) Application of radiocarbon method for dating of lime mortars. Geochronometria, 24, 2005, pp. 109-115

- NONNI, S.; MARZAIOLI, F.; SECCO, M.; PASSARIELLO, I.; CAPANO, M.; LUBRITTO, C.; MIGNARDI, S.; TONGHINI, C.; TERRASI, F. (2013) ${ }^{14} \mathrm{C}$ mortar dating: The case of the medieval Shayzar Citadel, Syria. Radiocarbon, 55 (2-3), 2013, pp. 514-525

- HUA, Q. (2009) Radiocarbon: A chronological tool for the recent past. Quaternary Geochronology, vol. 4, 2009, pp. 378-390 
- QUIRÓS CASTILLO, J.; MARZAIOLI, F.; LUBRITTO, C. (2011) Dating mortars: three medieval Spanish architectures. Arqueología de la Arquitectura, 0(8), 2011, pp. 13-24

- RINGBOM, Å.; HALE, L.; HEINEMEIER, J.; LINDROOS, A.; BROCK, F. (2006) The use of mortar dating in archaeological studies of Classical and Medieval structures. Proceedings of the Second International Congress on Construction History, vol. 3, 2006, pp. 2613-2633

- RINGBOM, Å.; HEINEMEIER, J.; LINDROOS, A.; BROCK F. (2011) Mortar dating and Roman pozzolana, results and interpretations. En RINGBOM, Å.; HOHLFELDER, R. L. (ed.) Building Roma Aeterna. Current Research on Roman Mortar and Concrete. Commentationes Humanarum Litterarum 128, 2011, pp. 187-208 (Proceedings of the conference, Roma, 27-29/03/2008)

- RINGBOM, A.; LINDROOS, A.; HEINEMEIER, J.; SONCK-KOOTA, P. (2014) 19 years of mortar dating: Learning from experience. Radiocarbon, 56 (2), 2014, pp. 619-635

- SANJURJO-SÁNCHEZ, J. (2016) Dating Historical Buildings: An Update on the Possibilities of Absolute Dating Methods. International Journal of Architectural Heritage, 10 (5), 2016, pp. 620-635

- SANTOS ARÉVALO, F. J. (2018a) Interpretación del Informe de Datación y Calibración [en línea] <http:// institucionales.us.es/solicitudescna/attachments/article/12/ Interpretaci\%C3\%B3n\%20del\%20Informe\%20de\%20 Dataci\%C3\%B3n\%20y\%20Calibraci\%C3\%B3n.pdf> [Consulta: 06/02/2018]

- SANTOS ARÉVALO, F. J. (2018b) Instrucciones para el envío de muestras para su datación por ${ }^{14} \mathrm{C}$ [en línea] <http:// institucionales.us.es/solicitudescna/attachments/article/12/ Instrucciones $\% 20$ para\%20 el\%20envio\%20de\%20 muestras\%204.0_180110.pdf> [Consulta: 06/02/2018]

- SONNINEN, E.; JUNGER, H. (2001) An improvement in preparation of mortar for radiocarbon dating. Radiocarbon 43 (2A), 2001, pp. 271-273

- STUIVER, M.; REIMER, P. J.; BRAZIUNAS, T. F. (1998) High-Precision Radiocarbon Age Calibration for Terrestrial and Marine Samples. Radiocarbon, 40, 1998, pp. 11271151

- TUBBS, LE; KINDER, TN. (1990) The use of AMS for the dating of lime mortars. Nuclear Instruments and Methods in Physics Research, Section B: Beam Interactions with Materials and Atoms, 52(3-4), 1990, pp. 438-441

- AENOR (2010) Norma UNE-EN 998-1:2010. Especificaciones de los morteros para albañilería. Parte 1: Morteros para revoco y enlucido, 2010
- AENOR (2012) Norma UNE-EN 998-2:2012. Especificaciones de los morteros para albañilería. Parte 2: Morteros para albañilería, 2012

- VAN STRYDONCK, M.; DUPAS, M.; DAUCHOTDEHON, M.; PACHIAUDI, CH.; MARECHAL, J. (1986) The influence of contaminating carbonate and the variations of $13 \mathrm{C}$ in mortar dating. Radiocarbon, 28 (2A), 1986, pp.702710 